\title{
MAINTENANCE OF ANTI-RETROVIRAL THERAPY (ART) TO HIV PATIENTS AND THEIR PREVENTIVE PRACTICES AGAINST COVID-19 PANDEMIC - A SYNDEMIC PERSPECTIVE FROM A HIV CENTER IN PAKISTAN
}

\author{
Saira Maroof, Humaira Mahmood*, Hira Nigar**, Syed Fawad Mashaddi, Asma Iftikhar*, Syma Arshad*** \\ Army Medical College/National University of Medical Sciences (NUMS) Rawalpindi Pakistan, *Armed Forces Post Graduate Medical Institute/National

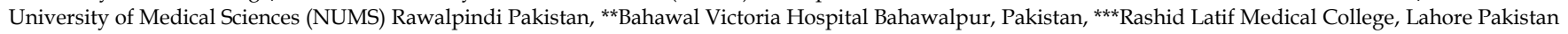

\section{ABSTRACT}

Objective: To see the implementation of designed strategy for uninterrupted supply of HIV treatment at time of COVID-19 pandemic along with the knowledge and preventive practices regarding COVID-19 among HIV positive patients to have baseline data for future interventions to control HIV-COVID-19 syndemic.

Study Design: Cross sectional study.

Place and Duration of Study: The HIV Center at Benazir Bhutto Shaheed Hospital, Karachi Pakistan, from Mar to May 2020. Methodology: A total of 100 patients who visited the center for medicines were interviewed. Participants were inquired about the availability of Antiretroviral Therapy (ART) during lockdown, discontinuity in treatment suffered during this pandemic, their preventive behaviour against COVID-19, most adopted prevention and source of information for this behavior.

Results: Among all the participants $72 \%$ had achieved viral suppression. As far as multi month dispensing was concerned $10 \%$ received ART for one month, $64 \%$ for 2 months and $18 \%$ for 3 months as per the strategy devised by Pakistan AIDS control in collaboration with UNAIDS. Out of total only $11 \%$ developed symptoms but later on tested negative on PCR test. Most commonly adopted personal protection adopted was face mask among $68 \%$ participants followed by hand washing and social distancing. All the participants were of the opinion that they received sufficient information regarding COVID-19, its prevention and mode of spread. The source of information was TV 60\%, HIV center $30 \%$ and both TV and HIV center $10 \%$.

Conclusion: It was found that all the patients got uninterrupted supply of anti-retroviral medicines. Despite sufficient knowledge regarding the disease they could not comply with prevention fully because of their occupational requirements.

Keywords: Anti-retroviral therapy, COVID-19, Human immune deficiency virus, Lockdown.

How to Cite This Article: Maroof S, Mahmood H, Nigar H, Mashaddi SF, Iftikhar A, Arshad S. Maintenance of Anti-Retroviral Therapy (ART) To HIV Patients and Their Preventive Practices Against COVID-19 Pandemic-A Syndemic Perspective from A HIV Center in Pakistan. Pak Armed Forces Med J 2021; 71(5): 1769-1773. doi: https://doi.org/10.51253/pafmj.v71i5.5357

This is an Open Access article distributed under the terms of the Creative Commons Attribution License (https://creativecommons.org/licenses/by-nc/4.0/), which permits unrestricted use, distribution, and reproduction in any medium, provided the original work is properly cited.

\section{INTRODUCTION}

In December 2019, a severe acute respiratory syndrome coronavirus 2 (SARS-CoV-2), emerged in China, in the city of Wuhan. It caused coronavirus disease (COVID-19), which has resulted in the catastrophic pandemic in modern history. ${ }^{1}$

COVID 19 can present as a wide spectrum, ranging from asymptomatic at one end to death at the other. In between theses extremes cases consist of having mild symptoms, from cough and fever to severe and life threatening acute respiratory distress syndrome (ARDS), sepsis and multi-organ failure. ${ }^{2}$ There are no current guidelines for specific treatment for COVID-19. In most of the cases only symptomatic treatment is required, though severe cases require admission to hospital for supportive management including mechanical ventilation. 3,4

Correspondence: Dr Saira Maroof, Assistant Professor of Community Medicine, Army Medical College, Rawalpindi Pakistan

Received: 17 Sep 2020; revision received: 28 Aug 2021; accepted: 01 Sep 2021
Evidence suggests that increasing age, hypertension, obesity and diabetes are risk factors for worse outcomes. However, it is not clear if people living with HIV (PLHIV) suffer from greater risk as compared to general population. 5,6

HIV/AIDS is a growing public health issue endangering lives of millions of people worldwide. HIV needs to be defeated through strong political commitments. Innovative strategies which involve use of modern technology and sufficient resources. HIV infection can lead to AIDS, if left untreated, due to decrease in number of CD4 T cells. AIDS is defined as a CD4 T-cell count $<200$ cells $/ \mathrm{ml}$ or the presence of an AIDS-defining illness. ${ }^{7}$ According to 2018 estimates, globally 37.9 million people are having HIV infection, in which 23.3 million are on antiretroviral therapy (ART) ${ }^{8}$, and almost $80 \%$, of those on treatment have successful viral suppression and patients are non-immune compromised if they adhere to ART regime, ${ }^{9}$ Despite this, PLHIV may be at risk of severe complications of COVID-19, if HIV infection is poorly controlled. There is paucity of 
evidence available on the impact of HIV on SARSCoV-2 infection and on COVID-19 outcomes. ${ }^{10}$

The current study has been designed to have an insight into implementation of designed strategy for non-interrupted supply of HIV treatment in time of pandemic along with the knowledge and preventive practices regarding COVID 19 among HIV positive patients to have baseline data for future interventions to control HIV- COVID-19 Syndemic.

\section{METHODOLGY}

It was a cross sectional study conducted at HIV/ AIDS Diagnostic and Treatment Center at Benazir Bhutto Hospital Rawalpindi. This Center works under Punjab AIDS Control Programme. It provides free of cost treatment facilities to all HIV patients and confidentiality is ensured to its best.

The patients who visited the center for medicines during March to May 2020, were approached and those who consented for participation were administered a self-structured questionnaire ensuring confidentiality by coding the data and keeping the filled proforma under lock and key.

\section{Inclusion Criteria}

Only those participants who were willing to participate and visited center for medicines were included.

\section{Exclusion Criteria}

Those who were reluctant to participate were not included in study.

In this way, a sample of 100 patients was interviewed using consecutive sampling. The demographic details pertained to age, gender, marital status, occupation, area of residence and any other medical conditions they were suffering from like DM, HTN, hepatitis B or C, TB, asthma.

The second part of questionnaire pertained to the situation arising due to lockdown, discontinuity in treatment if they had to suffer. They were also inquired about developing COVID-19 symptoms and if being tested for the virus.

The last part of questionnaire pertained to their preventive behavior, most commonly adopted prevention and the source of information regarding COVID19 preventions.

Ethical Review Committee at the Punjab AIDS Control Programme (PACP) was approached for ethical clearance. Permission for data collection was granted vide Punjab AIDS Control Program Letter No PACP/Admin/27498 dated 2 Sep 2020.
The data was entered and analyzed using Statistical Package for Social Sciences version-23. The quantitative variables like age, duration since diagnosis and duration since on Anti-Retroviral treatment were analyzed using mean and standard deviation or median with IQR. While qualitative variables like gender, occupation, area of residence, medical co-morbid and extent of adoption of preventive practices was measured in terms of frequencies and percentages. The $p$-value of $\leq 0.05$ was considered statistically significant.

\section{RESULTS}

Mean age of the participants was $34.06 \pm 10.69$ years (range: 17-62). The median duration since diagnosis of HIV was 24 months (IQR: 24 months), while the median duration since the Anti-Retroviral Treatment started was 24 months (IQR: 25 months). Among them $72 \%$ had achieved viral suppression while $28 \%$ had not yet achieved viral suppression. The demographic characteristics of the participants given in Table-I.

Table-I: Demographic characteristics of participants.

\begin{tabular}{|c|c|c|}
\hline \multicolumn{2}{|l|}{ Variable } & Frequency (n) \\
\hline \multirow{3}{*}{ Gender } & Males & 62 \\
\hline & Females & 13 \\
\hline & Transgender & 25 \\
\hline \multirow{3}{*}{ Marital Status } & Married & 76 \\
\hline & Unmarried & 22 \\
\hline & Divorced & 2 \\
\hline \multirow{5}{*}{$\begin{array}{l}\text { Educational } \\
\text { Status }\end{array}$} & Illiterate & 28 \\
\hline & Primary & 24 \\
\hline & Middle & 20 \\
\hline & Matriculate & 22 \\
\hline & Bachelors & 6 \\
\hline \multirow{10}{*}{ Occupation } & Labor/Daily wages & 25 \\
\hline & Drivers & 8 \\
\hline & Private business & 14 \\
\hline & Government Job & 3 \\
\hline & Sex Workers & 6 \\
\hline & Bagging & 12 \\
\hline & Dancers & 8 \\
\hline & Farmers & 2 \\
\hline & Housewives & 13 \\
\hline & Jobless & 9 \\
\hline \multirow{4}{*}{$\begin{array}{l}\text { Area of } \\
\text { Residence }\end{array}$} & Tehsil Rawalpindi & 78 \\
\hline & Tehsil Gujar Khan & 15 \\
\hline & Tehsil Taxila & 6 \\
\hline & Lahore & 1 \\
\hline
\end{tabular}

Among 100 participants 57\% were smokers, 40\% were nonsmokers and 3\% were involved in substance abuse as well as smoking. Rest of the chronic medical conditions of the participants are given in the Figure.

During lockdown, the availability of ART was to be ensured and as per government policy multi 


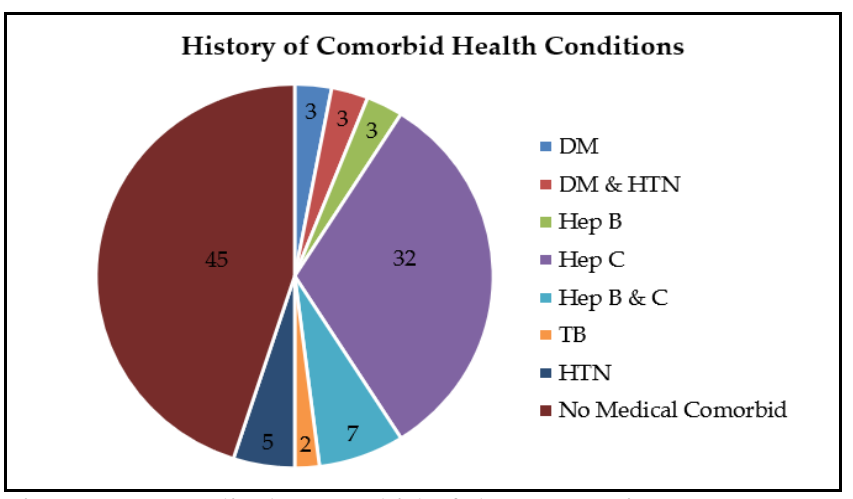

Figure: Past medical co-morbid of the HIV patients.

months, dispensing was advised. So among the participants $18 \%$ were issued medicines for 3 months, $64 \%$ for 2 months while $16 \%$ were issued for only 1 month, there was no disruption in the availability of medicines during lockdown. Almost 100\% could continue their treatment without any discontinuation.

Beyond availability of medicines and multi month dispensing, it was very important to know about the health of the patients, when inquired about any COVID-19 symptoms it was found that $89 \%$ didn't develop any kind of symptoms while $1 \%$ developed symptoms like fever and cough, sought health care and was subsequently tested negative on PCR test.

The most important measure against COVID-19 were public health preventive measures. When inquired about practicing social distancing, it was found that $62 \%$ did practice it, $25 \%$ didn't practice while $13 \%$ said that even though they wanted to practice it but couldn't practice it because of their occupational requirements. Family support was available to $56 \%$ and $44 \%$ were not supported by their families in practicing social distancing. Rest of the preventive practices are given in Table-II.

Table-II: Preventive measures adopted by the participants.

\begin{tabular}{l|c|c}
\hline Preventive Measure & Frequency (n) \\
\hline \multirow{3}{*}{$\begin{array}{l}\text { Mostly adopted } \\
\text { practice }\end{array}$} & Face mask & 68 \\
\cline { 2 - 3 } & $\begin{array}{c}\text { Face mask , Hand } \\
\text { washing }\end{array}$ & 20 \\
\cline { 2 - 3 } & Hand washing & 12 \\
\hline \multirow{4}{*}{$\begin{array}{l}\text { Work Practice during } \\
\text { lock down }\end{array}$} & $\begin{array}{c}\text { Going out daily } \\
\text { for work }\end{array}$ & 63 \\
\cline { 2 - 3 } & $\begin{array}{c}\text { Working from } \\
\text { home }\end{array}$ & 3 \\
\cline { 2 - 3 } & Not working at all & 21 \\
\cline { 2 - 3 } & Housewives & 13 \\
\hline \multirow{2}{*}{$\begin{array}{l}\text { Use of face mask } \\
\text { while going out for } \\
\text { essential work /duty }\end{array}$} & Yes & 82 \\
\cline { 2 - 3 } & No & 18 \\
\hline
\end{tabular}

As per the data available, it was found that COVID-19 had badly affected the people having chronic medical issues of their health. When inquired about the fear of getting infection because of community spread $47 \%$ said yes while $53 \%$ said no, while $45 \%$ said to have fear of death due to this pandemic and 55\% said no such fears.

Media had played great role in raising awareness among people about COVID-19. Among our participants $100 \%$ were of the opinion that sufficient information has been provided about the disease and its prevention and most common source was TV $60 \%$, HIV center $30 \%$ and both TV and HIV center in $10 \%$ of the cases as shown.

\section{DISCUSSION}

COVID-19 pandemic is a rapidly emerging situation and the world is still learning about its behavior among various age groups and also among people suffering from various diseases. Similar is the case with HIV patients. Patients who are elderly, having underlying medical conditions, have low CD4 and those who are not on effective Anti-Retroviral Therapy (ART) are at higher risk to contract the virus. Till such evidence is gathered there is need to have a precautionary approach and put adequate preventive measures in place to prevent HIV positive persons from the potential disastrous effects of the syndemic. Syndemic refers to any two or more diseases in the same individual at a point in time that could act synergistically to magnify and augment the disease burden. ${ }^{11}$

Among key populations, HIV/AIDS in Pakistan silently shifted from a "low prevalence, high risk" to a "concentrated epidemic" in mid-2000s. With over 130,000 people living with HIV (PLHIV) in Pakistan, only an estimated 19,000 are registered in the treatment centers and less than 10,000 PLHIV are on antiretroviral therapy.12 COVID 19 started to affect Pakistan in late March, thus Pakistan was fortunate enough to have time for the planning of the continuity of treatment for HIV/AIDS patients. The strategy developed by the APLHIV, together with UNAIDS and Pakistan's National AIDS Control Programme, groups all people living with HIV who are on treatment into three groups: red (people with a supply of antiretroviral therapy for less than two weeks); yellow (people with a supply of antiretroviral therapy for a month); and green (people with a supply of antiretroviral therapy for more than a month). These groups are then used to prioritize who receives packages of antiretroviral 
therapy, provided by the National and Provincial AIDS Control Programs. ${ }^{13,14}$

All the efforts were made to ensure uninterrupted supply of anti-retroviral drugs. Pakistan Common Management Unit for AIDS, TB and Malaria in collaboration with UNAIDS and Global Fund to Fight AIDS has tried maximum to ensure buffer stock in case of disruption in medicine imports. ${ }^{15}$

In our study, median age of the HIV patients was 34 years as compared to a study conducted among COVID positive HIV patients where the median age was 61 years. This could be due to the younger population of Pakistan. ${ }^{16}$ In our study the most common comorbid condition was hepatitis C among 32\% and hepatitis B and hepatitis C both among 7\% of the participants as compared to the study conducted in New York where the most common condition was HTN 38\% followed by DM 27\% among the HIV patients. This is obviously due to past needle sharing/common syringe use among our patients while the burden of NCDs already known in the European countries. ${ }^{16}$

There could be a substantial rise in the number of deaths among HIV patients among high burden countries. This partly could be due to interruption in treatment and partly due to noncompliance to NPIs. ${ }^{17}$ In our study however it was found that all $100 \%$ patients could access the center and were provided with ART without any discontinuity in treatment as compared to a study conducted by Stephanie et al, that patients had to struggle to access ART during COVID-19 pandemic. This might be because of the lessons learned from the countries where COVID-19 had already spread and better preparedness by the government to facilitate HIV patients. ${ }^{18}$

During COVID-19 pandemic the most desired upon prevention aspect was physical distancing and hand hygiene. In our study the most commonly adopted measure was using facemask among $100 \%$ patients however the physical distancing and work from home was followed by only $16 \%$ among which $13 \%$ were females. This was not possible because most of the patients' livelihood was linked to daily wages. ${ }^{19}$

In our study $11 \%$ developed COVID-19 like symptoms, tested negative on PCR, and didn't require hospitalization as compared to a study in Chicago where $14.5 \%$ tested positive, out of which $75 \%$ got hospitalized and $12.5 \%$ got admitted to intensive care unit. ${ }^{20}$

There is broadcasting freedom to Pakistani media and it played a great role in sharing information regar- ding COVID-19 which was timely and based on facts as well. When patients were inquired about the source of information and behavioral adoptive measures, it was observed that TV was most powerful as stated by $60 \%$ of patients in providing timely and correct information followed by HIV center. ${ }^{21}$

\section{CONCLUSION}

In our study it was found out that COVID-19, being a new pandemic the, success was associated with strict implementation of prevention measures. HIV patients also tried to abide by the personal protection including facemasks, hand washing and social distancing. However, because of their livelihood requirements/occupational needs they couldn't strictly work from home and have to go out but still they tried to implement the prevention measures. As far as the state is concerned despite lockdown, the ART supply and dispensing continued and there was no disruption in treatment among any of the HIV patients.

\section{Conflict of Interest: None.}

\section{Authors' Contribution}

SM: Results, statistical analysis, HM: Introduction, literature review, HN: Data collection, coordination, questionnaire design, SFM: Discussion, AI: Data enty, cleaning, SA: Overall review, proof reading.

\section{REFERENCES}

1. Steffens I. A hundred days into the coronavirus disease (COVID19) pandemic. Euro Surveill 2020; 25(14): 2000550.

2. Zaim S, Chong JH, Sankaranarayanan V, Harky A. COVID-19 and Multi-Organ Response. Curr Probl Cardiol 2020; 45(8): 100618.

3. Jordan RE, Adab P, Cheng KK. Covid-19: risk factors for severe disease and death. BMJ 2020; 368(2): m1198.

4. Zheng Z, Peng F, Xu B, Zhao J, Liu H, Peng J, et al. Risk factors of critical \& mortal COVID-19 cases: A systematic literature review and meta-analysis. J Infect 2020; 81(2): e16-e25.

5. Vishnevetsky A, Levy M. Rethinking high-risk groups in COVID-19. Mult Scler Relat Disord 2020; 42(1): 102139.

6. Cooper TJ, Woodward BL, Alom S, Harky A. Coronavirus disease 2019 (COVID-19) outcomes in HIV/AIDS patients: a systematic review. HIV Med 2020; 21(9): 567-577.

7. Siedner MJ, Triant V. Undetectable=UnTransmittable and Your Health: The personal benefits of early and continuous therapy for HIV infection. J Infect Dis 2019; 219(2): 173-176.

8. UNAIDS. Global AIDS Monitoring 2019: Indicators for Monitoring the 2016 Political Declaration on Ending AIDS. Geneva, Switzerland: UNAIDS; 2019, [Internet] Available at: https:// www.unaids.org/en/resources/documents/2020/global-aidsmonitoring-guidelines (Accessed on May 15, 2020)

9. Joob B, Wiwanitkit V. SARS-CoV-2 and HIV. J Med Virol 2020; 92(9): 1415-1418.

10. World Health Organization (WHO). Patient safety curriculum guide: Multi-professional edition. [Internet] Available at: https://www.who.int/patientsafety//curriculum/PSP_Curri culum. / 2011 [Accessed on November 27, 2019]

11. Candice KK, Joel DE. HIV and Tuberculosis: a Deadly Human Syndemic. Clinic Microbiol Rev 2011; 24(2): 351-376.

12. Hafeez T, Riaz SH, Ali I, Irum N. A study of knowledge and attitude of health care providers working at tertiary care 


\section{Anti-Retroviral Therapy}

hospitals of Lahore, Pakistan (having HIV/AIDS treatment facility) towards HIV/AIDS. Acta Medica Int 2017; 4(1): 124-30.

13. Unaids.org. "We must ensure that HIV treatment adherence is not compromised"-keeping people in Pakistan on HIV treatment. UNAIDS; 2020, [Internet] Available from: https://www. unaids.org/en/resources/presscentre/featurestories/2020/april /20200429_pakistan [Accessed on November 27, 2019]

14. U.S. Agency for International Development. Novel Coronavirus (COVID-19). U.S. Agency for International Development. 2020 [Internet] Available from: https://www.usaid.gov/coronavirus [Accessed on November 30, 2019]

15. Unaids.org. Keeping HIV treatment available in Pakistan during COVID-19 2020, [Internet] Available from: https://www. unaids.org/en/resources/presscentre/featurestories/2020/april /20200415_pakistan [Accessed on November 30, 2019]

16. Sigel K, Swartz T, Golden E, Paranjpe I, Somani S, Richter F, et al. COVID-19 and people with HIV infection: outcomes for hospitalized patients in New York City. Clin Infect Dis 2020; 71(11): 2933-2938.
17. Hogan AB, Jewell BL, Sherrard-Smith E, Vesga JF, Watson OJ, Whittaker C, et al. Potential impact of the COVID-19 pandemic on HIV, tuberculosis, and malaria in low-income and middleincome countries: a modelling study. Lancet Glob Health 2020; 9(2): e1132-e1141.

18. Shiau S, Krause KD, Valera P, Swaminathan S, Halkitis PN. The burden of COVID-19 in people living with HIV: a syndemic perspective. AIDS Behav 2020; 24(8): 2244-2249.

19. Eaton LA, Kalichman SC. Social and behavioral health responses to COVID-19: lessons learned from four decades of an HIV pandemic. J Behav Med 2020; 43(3): 341-345.

20. Ridgway JP, Schmitt J, Friedman E, Taylor M, Devlin S, McNulty $\mathrm{M}$, et al . HIV Care Continuum and COVID-19 Outcomes among People Living with HIV during the COVID-19 Pandemic, Chicago, IL. AIDS Behav 2020; 24(10): 2770-2772.

21. Islam AN, Laato S, Talukder S, Sutinen E. Misinformation sharing and social media fatigue during COVID-19: An affordance and cognitive load perspective. Technol Forecast Soc Change 2020; 159(2): 120201 